\title{
Ki-67 Expression by Immunohistochemistry and Quantitative Real-Time Polymerase Chain Reaction as Predictor of Clinical Response to Neoadjuvant Chemotherapy in Locally Advanced Breast Cancer
}

\author{
Prihantono Prihantono, ${ }^{1}$ Mochammad Hatta, ${ }^{2}$ Christian Binekada, ${ }^{1}$ Daniel Sampepajung, \\ Haryasena Haryasena, ${ }^{1}$ Berti Nelwan, ${ }^{3}$ Andi Asadul Islam, ${ }^{1}$ and Andi Nilawati Usman ${ }^{4}$ \\ ${ }^{1}$ Department of Surgery, Faculty of Medicine, Hasanuddin University, Makassar, Indonesia \\ ${ }^{2}$ Biology Molecular and Immunology Laboratory, Faculty of Medicine, Hasanuddin University, Makassar, Indonesia \\ ${ }^{3}$ Department of Pathology Anatomy, Faculty of Medicine, Hasanuddin University, Makassar, Indonesia \\ ${ }^{4}$ Halal Center, Faculty of Public Health, Hasanuddin University, Makassar, Indonesia
}

Correspondence should be addressed to Andi Nilawati Usman; nilawatiandi@gmail.com

Received 12 December 2016; Revised 2 March 2017; Accepted 27 July 2017; Published 31 October 2017

Academic Editor: Subodh Kumar

Copyright (c) 2017 Prihantono Prihantono et al. This is an open access article distributed under the Creative Commons Attribution License, which permits unrestricted use, distribution, and reproduction in any medium, provided the original work is properly cited.

\begin{abstract}
Background. Chemotherapy has become a standard of treatment in managing breast cancer. To achieve proper treatment for the right patients, the predictive marker is needed. Ki-67 is a biomarker of proliferation for solid tumor. Studies mentioned association of Ki-67 expression with chemotherapy response. The study aims are to evaluate whether Ki-67 expression detected by immunohistochemistry (IHC) and quantitative real-time polymerase chain reaction (qRT-PCR) may predict clinical response to neoadjuvant chemotherapy in breast cancer. Methods. This study utilized a longitudinal study. IHC and qRT-PCR methods were used for detection of Ki-67 expression. Chemotherapy response was calculated using RECIST. Data were analyzed with Chi-square and Wilcoxon's test. Results. There were 48 subjects in this study. Analysis of Ki-67 expression with chemotherapy response has a significant correlation with $p=0.025(<0.05)$, OR: 1.69, confidence interval (95\% CI) 1.022-2.810. Analysis of Ki-67 mRNA expression with chemotherapy response has a significant correlation $p=0.002(<0.05)$, OR: 6.85 , confidence interval $(95 \% \mathrm{CI})$ 1.064-44.193. Detection of Ki-67 expression using IHC and qRT-PCR has similar results, $p=0.012(<0.05)$. Conclusion. These results suggest that Ki-67 expression detected by both IHC and qRT-PCR is considered to be a predictor of clinical response to neoadjuvant chemotherapy in locally advanced breast cancer.
\end{abstract}

\section{Introduction}

Breast cancer is cancer with the highest incidence in Indonesia, with an incidence of 18.6 patients in 100,000 people annually [1]. Most of the patients came in advanced stages, $63 \%$ were in stage III and stage IV by the time they were diagnosed [2]. Neoadjuvant chemotherapy has become a standard in managing locally advanced breast cancer [3].

Patients that have the same breast cancer stage and chemotherapy regiment may not have the same result. To give precise chemotherapy regimens, we need a predictive marker
[4]. An ideal biomarker must differentiate tumor response towards certain chemotherapy agent before chemotherapy procedure is done so that we can avoid unnecessary therapy and toxic effect of the regiment [5]. Finding a biomarker which may predict chemotherapy response for breast cancer was still a challenge [6].

$\mathrm{Ki}-67$ is a core protein which was expressed in G1, S, G2, and $\mathrm{M}$ phase and has been assigned as a solid tumor proliferation marker. Tumor proliferation activity shown with a Ki-67 overexpression in breast cancer is related to poor prognosis and also is predictive of neoadjuvant chemotherapy response 
[7]. The rate in Ki-67 relative proportion can be observed along chemotherapy and correlates with clinical and pathological response in breast cancer [8].

Breast cancer is a heterogenic disease, based on gene expression profile or breast cancer immunohistochemistry, divided into several subtypes, that is, Luminal A, Luminal B, Her-2, and triple negative. Every subtype has a different response and aggressiveness toward systemic therapy. St. Galen consensus (2011) approved that the kind of subtype influences the breast cancer chemotherapy response $[9,10]$.

Because of the importance of predictive marker in managing breast cancer and lack of data about Ki-67 expression in Indonesia, we are interested in evaluating the relationship of Ki-67 expression detected by IHC and qRT-PCR in breast cancer tissue prior to chemotherapy with chemotherapy response in breast cancer patients in Makassar Indonesia.

\section{Material and Methods}

2.1. Material. We acquired samples from breast cancer patients who received chemotherapy in Surgical Oncology Department of Wahidin Sudirohusodo Hospital, Makassar, from October 2014 until September 2015. The inclusion criteria were women with locally advanced breast cancer and invasive ductal carcinoma and women receiving cyclophosphamide-doxorubicin-5FU [11] regimen.

We performed clinicopathology data collection which involved age and grading. Then we performed immunohistochemistry panel examination of ER, PR, Her2, and Ki-67. We also detect Ki-67 expression using qRT-PCR. Chemotherapy response was measured clinically by using a caliper, at the moment before starting the 1st cycle of chemotherapy and three weeks after the 3rd cycle of chemotherapy. Data were collected, managed, analyzed, and presented in table and narration form, and then we compared them with the result of other studies.

2.2. Clinical Response Criteria. Clinical response in this study is classified into two categories: nonresponsive, according to RECIST, that is, stable disease or progressive disease, which is defined as reduced tumor size $<30 \%$, the size of the tumor remaining the same, increase of the tumor size, or discovering a new tumor; responsive, according to RECIST, that is, complete response or partial response which is defined as disappearance of tumor mass or at least the reduction of tumor size by up to $30 \%$ and no new tumors.

\subsection{Immunohistochemical Staining. Immunohistochemical} staining technique is employing polymer-based methods. The primary antibodies and dilutions were used (DakoCytomation, Glostrup, Denmark): ER (clone 1D5, 1:100), PR (clone PgR636, 1:100), and Ki-67 (MIB-1, 1:200) [12, 13]. Paraffin blocks are cut with a thickness of 4-6 microns and placed in a special glass slide coated poly-L-lysine. Deparaffinize slides in Xylol solution 2x, every 15 minutes. Rehydrate slides in alcohol-rise $100 \%, 95 \%, 90 \%, 80 \%$, and $70 \%$, respectively, for 5 minutes, then drain. Heat-induced antigen retrieval (HIER): insert slides in a solution of citric acid $0.01 \mathrm{pH} 6.0$; heat in microwave for 10 minutes, and then chill. Wash slides with
PBS. Block endogenous peroxidase by immersing slides in $0.3 \% \mathrm{H} 2 \mathrm{O} 2$ solution for 30 minutes at room temperature. Wash slides in PBS. Blocking normal horse serum was done by dripping a solution of $1 \%$ normal horse serum and letting it stand at room temperature for 30 minutes. Wash slides with PBS. Drip slides with primary antibody AE $1 / 3$; enter them into the humid incubation chamber to be incubated in the room overnight. Wash slides with PBS 3 times, each for 5 minutes. Drip slides with secondary antibody solution, for 60 minutes at room temperature. Wash slides with PBS 3 times, each for 5 minutes. Drip slides with a solution of polymerantibody-peroxidase complex, and incubate them at room temperature for 30 minutes. Wash slides with PBS 3 times, each for 5 minutes. Drip slides with DAB solution. Incubate them at room temperature. Counterstain with hematoxylin. Dehydrate in graded alcohol 70\%, 80\%, 90\%, 95\%, and 100\%, respectively, for 3 minutes. Immerse the slides in Xylol 2x, each for 10 minutes. Mount and cover them with a glass deck. The results are obtained after the sample is checked by a light microscope up to $10 \times 40$ magnification $[13,14]$.

2.4. Immunohistochemistry Interpretation. Staining intensity and percentage of positive nuclei are recorded after manually segmenting tumor from the stroma. Tumors with ER/PR Remmele scores greater than 3 or positive nuclei greater than $1 \%$ were considered hormone receptor-positive [13]. When membrane staining is observed in $>10 \%$ of tumor cells, Her 2 is positive, and if less than $10 \%$ membrane staining is observed then Her2 is negative. Ki-67 is negative if there is less than $14 \%$ of nuclei staining and positive if $\geq 14 \%[13,15]$.

2.5. Nucleic Acid Isolation. Extraction of nucleic acid from breast cancer tissue was performed using diatom guanidinium isothiocyanate ( $\mathrm{GuSCN}$ ) method. The sample volume of about $100 \mathrm{ug} / \mathrm{ul}$ breast cancer tissue was added to $900 \mathrm{~mL}$ of "L6" solution which consists of $120 \mathrm{~g}$ guanidinium thiocyanate (GuSCN) (Fluka Chemie AG, Buchs, Switzerland, cat number 50 990), $100 \mathrm{ml}$ of $0.1 \mathrm{M}$ Tris-HCl, pH 6.4, $22 \mathrm{ml}$ 0.2 M ethylenediaminetetraacetate (EDTA), $\mathrm{pH} 8.0$, and $2.6 \mathrm{~g}$ Triton X-100 (Packard, Instruments) with a final concentration of $50 \mathrm{mM}$ Tris- $\mathrm{HCl}, 5 \mathrm{M}$ GuSCN, $20 \mathrm{mM}$ EDTA, and $0.1 \%$ Triton $\mathrm{X}-100$. Then $20 \mathrm{~mL}$ diatom suspension was added which consists of $50 \mathrm{ml}$ of $\mathrm{H} 2 \mathrm{O}$ and $500 \mathrm{~mL}$ of $32 \%$ (w/v) "Celite" ("diatoms") (Jansen Chimica, Beerse, Belgium, 10.846.79). $20 \mathrm{~mL}$ suspension of this diatom can bind $10 \mathrm{ug}$ DNA tissue, and it is then vortexed and centrifuged in $1.5 \mathrm{ml}$ Eppendorf tube with a speed of 13,000 rpm for 15 seconds. The supernatant was discarded, and the sediment was washed with "L2" solution consisting of $120 \mathrm{~g} \mathrm{GuSCN}$ in $100 \mathrm{ml}$ of $0.1 \mathrm{M}$ Tris- $\mathrm{HCl}$, $\mathrm{pH}$ 6.4, by adding $1 \mathrm{ml}$ of "L2" solution. Furthermore, vortexing and centrifugation at 13,000 rpm for 15 seconds were performed; then wash the sediment 2 times with an "L2" solution, followed by washing with $1 \mathrm{ml}$ of $70 \%$ ethanol 2 times and $1 \mathrm{ml}$ acetone. The result is then heated in a water bath at a temperature of $56^{\circ} \mathrm{C}$ for 10 minutes. Then $60 \mathrm{~mL}$ solution of "TE" was added which consists of $1 \mathrm{mM}$ EDTA in $10 \mathrm{mM}$ Tris- $\mathrm{HCl}, \mathrm{pH} 8.0$; then vortexing is done and centrifugation is continued at a speed of $13,000 \mathrm{rpm}$ for 2 minutes. Then the solution was incubated in the oven for 
10 minutes at a temperature of $56^{\circ} \mathrm{C}$. Then vortexing and centrifugation for 30 seconds at a speed of 13,000 rpm were conducted, and the supernatant was taken. The supernatant from this process will result in nucleotide extraction and was stored at $-800^{\circ} \mathrm{C}$ before PCR analysis $[16,17]$.

2.6. Expression mRNA Ki67 by Real-Time PCR. Detection of mRNA expression of Ki-67 was done according to Realtime PCR method previously described by Mitas, 2001, and Potemski, 2006. The process of oligonucleotide primers was specific for the gene, that is, housekeeping gene GAPDH (internal control). Detection of mRNA Ki-67 gene was performed using specific primers forward and reverse PCR protocols: Ki-67 forward: TCCTTTGGTGGGCACCTAAGACCTG and Ki-67 reverse: TGATGGTTGAGGTCGTTCCTTGATG. Cycle RT-PCR for Ki-67 was $94^{\circ} \mathrm{C}$ for 3 minutes; $94^{\circ} \mathrm{C}$ for 30 seconds, 38 cycles; and the next step is PCR: $51^{\circ} \mathrm{C}$ for 30 seconds. Also, specific primers of housekeeping genes used GAPDH forward: TGAGTGCTGTCTCCATGTTTGA and GAPDH reverse: TCTGCTCCCCACCTCTAAGTTG. QRT-PCR used qRT-PCR Green Master Mix Kit, one stage. This protocol was optimized for instrument MX4000. Protocol was adjusted by using the instrument by changing the dye dilution based on the instruction manual and following the recommended instrument factory for RT-PCR cycle program.

Passive reference dye was included in the reaction diluted 1:500. The solution containing the dye was kept away from light, diluted 2x by SYBR Green QRT-PCR Master Mix, and stayed on the ice. Following the initial melting master mix, the unused portion is stored at $40^{\circ} \mathrm{C}$ with the following note: avoid repeating freeze-liquid cycles. Reaction experiment was prepared by adding the following components. Make a mixture of reagents to the reaction using some components such as the following: the mixture of reagents to take a final volume of $25 \mathrm{~mL}$ (including experimental RNA), $12.5 \mathrm{~mL}$ of 2x SYBR Green QRT-PCR master mix plus $\times \mathrm{mL}$ of early primary (optimized concentration) plus nuclease-free $\mathrm{PCR}$ - the rate of the primary end $\mathrm{mL} \mathrm{H} 2 \times$ (optimized concentration), 0,375 $\mathrm{mL}$ reference dye solution from step 1 (optional), and $1.0 \mathrm{~mL}$ of RT/RNase enzyme mixture $50 \mu \mathrm{l}$ total blocks with a reaction volume can also be used. The reaction was mixed gently so as not to form bubbles (do not rotate), and then the mixture is distributed to a test tube experiment by adding $x \mathrm{~mL}$ RNA in each of the test tube experiments. The reaction was mixed gently so as not to form bubbles (not rotated). Reactions were centrifuged briefly, and the reaction was placed in the instrument, and the PCR program is ready to run using real-time PCR machine (CFX Connect System, Bio-Rad Laboratories, real-time PCR 96-well 0,1 ml, USA). Each sample was measured in triplicate [17-19].

2.7. Statistical Analysis. Data was analyzed using SPSS (Statistical Package for Social Sciences). Samples were analyzed using Chi Square and Wilcoxon's test. This study has an ethical approval from Health Research Ethics Committee of Medical Faculty of Hasanuddin University, RSPTN UH, dan RSUP
TAble 1: Patient characteristics.

\begin{tabular}{lcc}
\hline Characteristics & Number (\%) & p value \\
\hline Age & & \\
$\quad \leq 50$ & $27(56.3)$ & $0.076^{*}$ \\
$>50$ & & \\
Grade & $8(16.7)$ & $0.057^{*}$ \\
$\quad$ Low grade & $26(54.2)$ & \\
$\quad$ Moderate & $14(29.2)$ & \\
$\quad$ High grade & & \\
Subtype & $10(20.8)$ & \\
$\quad$ Luminal A & $20(41.7)$ & \\
Luminal B & $14(29.2)$ & \\
Her2 & $4(8.3)$ & $0.021^{*}$ \\
Triple negative & & \\
Ki-67 (SD) & $26(54.2)$ & $0.031^{* *}$ \\
Positive & $22(45.8)$ & \\
Negative & & \\
Mean of tumor size (SD) & $12.60(0.40)$ & \\
Before chemotherapy & $08.06(0.20)$ & \\
After chemotherapy & &
\end{tabular}

${ }^{*}$ Chi Square statistical test; ${ }^{* *}$ Wilcoxon's statistical test; $\mathrm{SD}=$ standard deviation.

Dr. Wahidin Sudirohusodo after lengthy discussion and evaluation, with a registration number 1659/H4.8.4.5.31/PP36KOMETIK/2015.

\section{Results}

3.1. Characteristics of Respondents. The research was done in the period from October 2014 to September 2015; subjects were breast cancer patients who met the inclusion-exclusion criteria. Of all samples collected, 48 samples were examined by immunohistochemistry method and 30 samples were tested by qRT-PCR examination. Characteristics of patients were all presented with clinical stage III A and stage III $\mathrm{B}$ at the time of initial diagnosis: 30 patients $(62.5 \%)$ who were responsive to neoadjuvant chemotherapy and 18 patients (37.5\%) who were nonresponsive. Breast cancer patient characteristics are shown in Table 1.

3.2. A Representative of Microphotographs of ER, PR, HER2, and Ki67 Immunostaining in Invasive Ductal Carcinoma. The representation of microphotographs of ER, PR, HER2, and Ki67 immunostaining of this research is shown in Figure 1. Microphotographs show nuclei staining in tumors with ER/PR positive, membrane staining in Her2 positive, and nuclei staining in the Ki-67 positive.

3.3. Amplification Curve, Melting Peak, and Melting Curve of mRNA Ki67 in Invasive Ductal Carcinoma Detected Using $q R T-P C R$. Figures 2 and 3 show amplification curve, melting peak, and melting curve of mRNA Ki67 in invasive ductal carcinoma detected using qRT-PCR. 


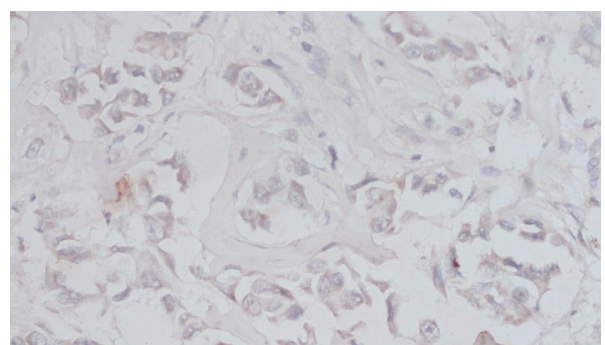

ER-

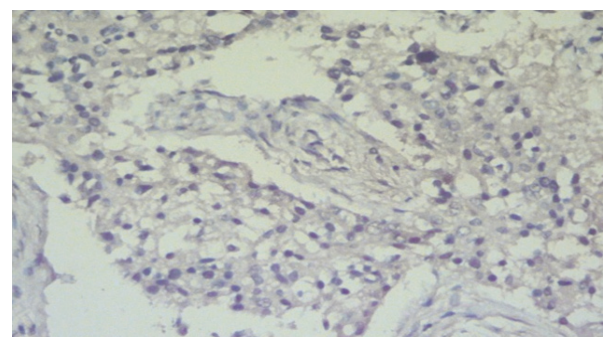

PR-

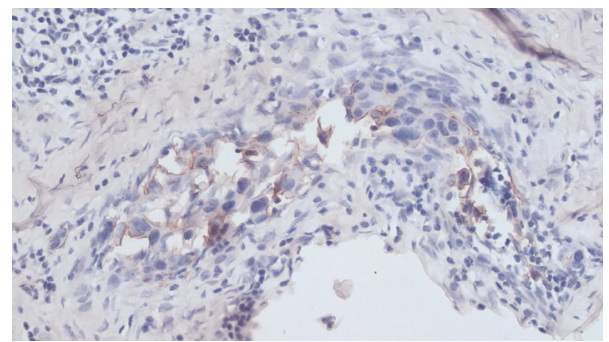

HER2-

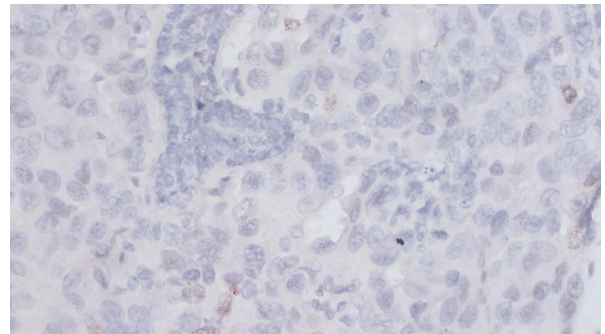

Ki67-

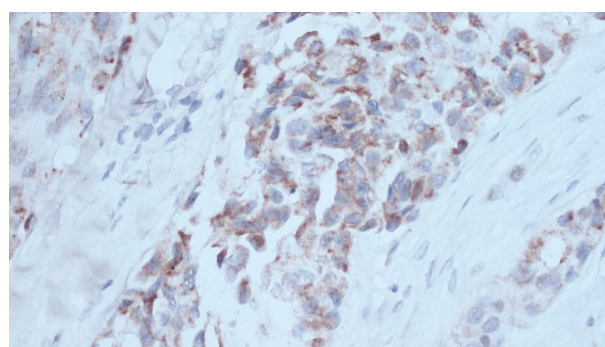

ER+

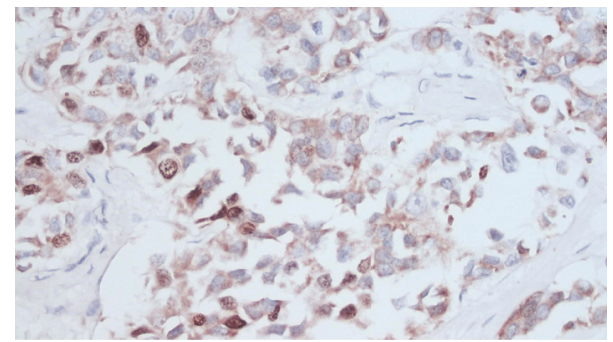

PR+

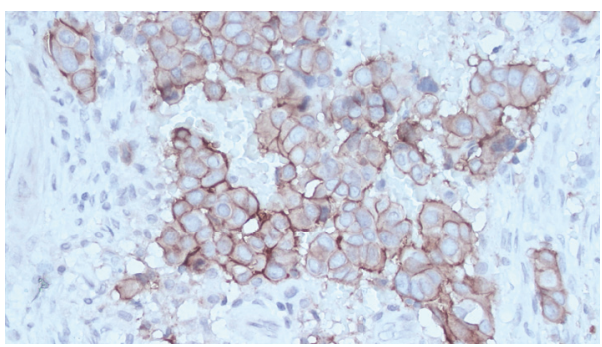

HER 2+

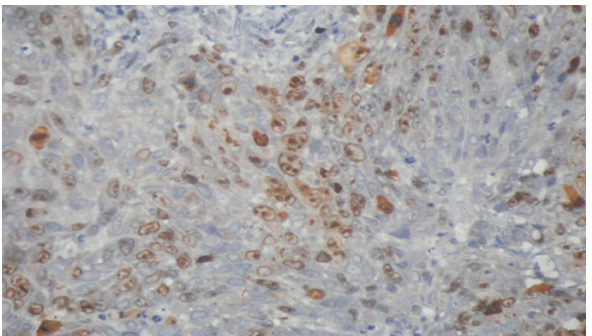

Ki67+

FIGURE 1: Microphotographs of ER, PR, HER2, and Ki67 immunostaining in invasive ductal carcinoma.
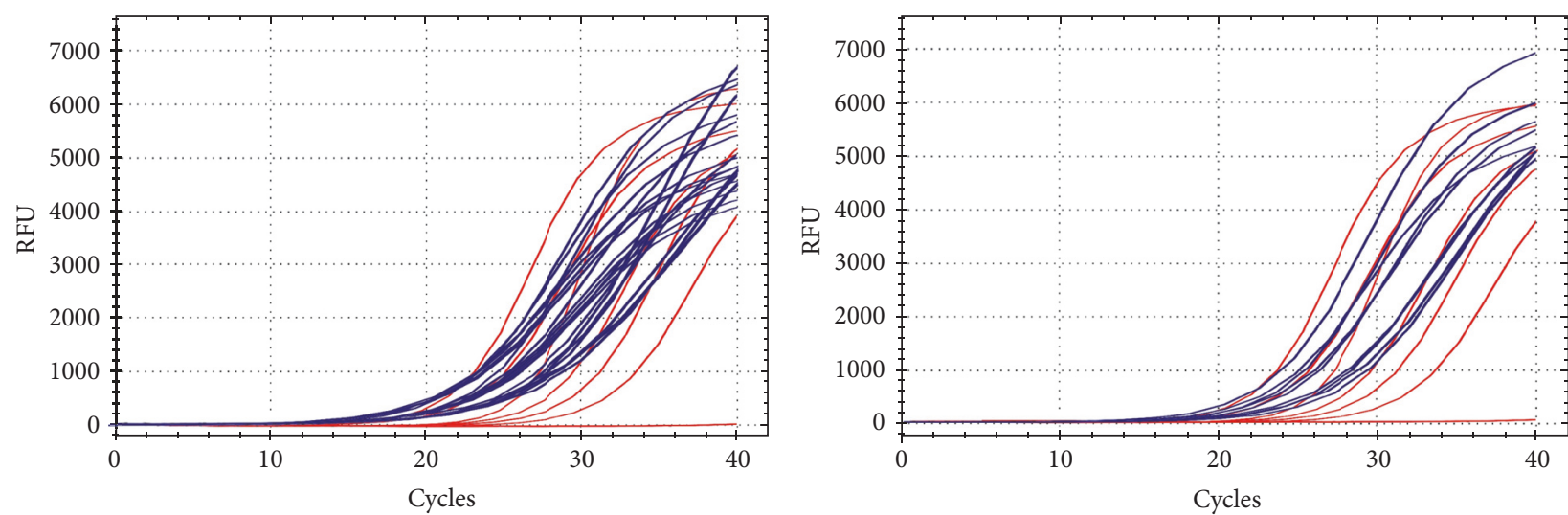

Figure 2: Amplification curve of Ki-67 mRNA expression. 

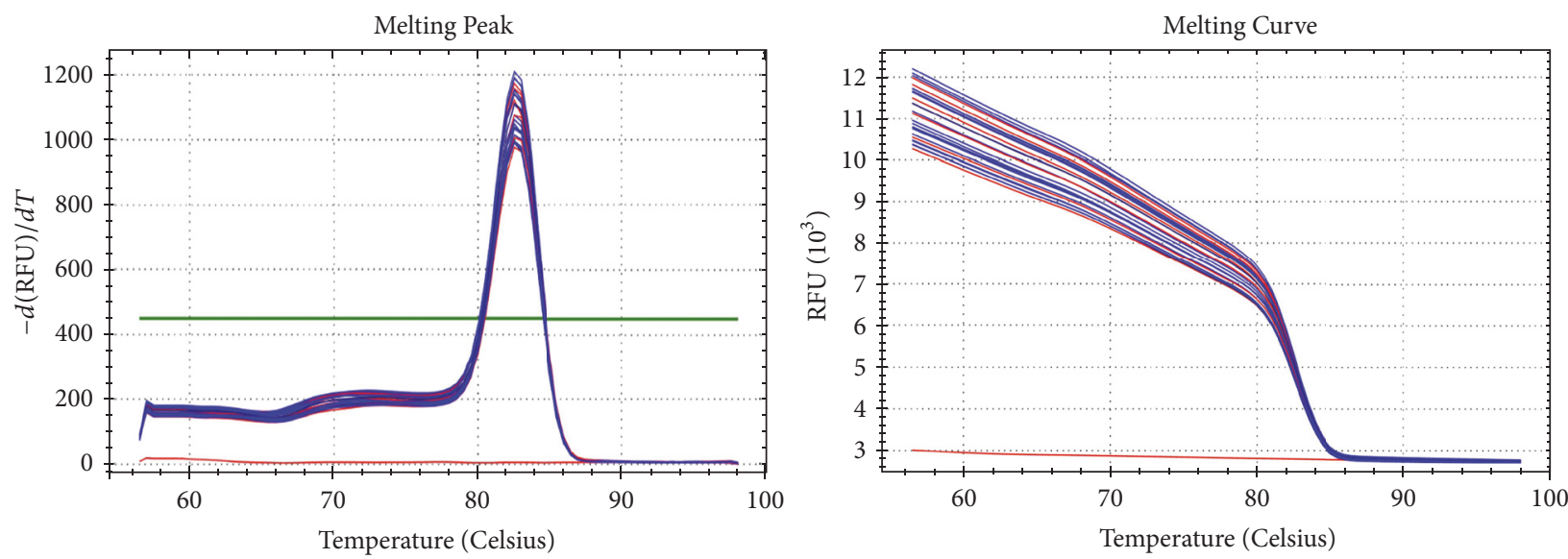

Figure 3: Melting peak and melting curve of Ki-67 mRNA expression.

TABLE 2: Relation of Ki-67 expression with chemotherapy response in breast cancer.

\begin{tabular}{lccc}
\hline \multirow{2}{*}{ Ki-67 expression } & \multicolumn{2}{c}{ Chemotherapy response } & \multirow{2}{*}{ Total } \\
& Responsive & Nonresponsive & \\
\hline Positive & $20(76.9 \%)$ & $6(23.1 \%)$ & $26(100 \%)$ \\
Negative & $10(45.5 \%)$ & $12(54.5 \%)$ & $22(100 \%)$ \\
\hline Total & $30(62.5 \%)$ & $18(37.5 \%)$ & $48(100 \%)$ \\
\hline
\end{tabular}

Chi-square $\chi^{2}=5.035 ; \mathrm{df}=1 ; p=0.025(p>0,05)$.

3.4. Relation of Ki-67 Expression with Neoadjuvant Chemotherapy Response. To find out whether the Ki-67 expression has a relationship with clinical response to neoadjuvant chemotherapy in breast cancer, we used bivariate analysis, which can be seen in Table 2 .

Analysis of Ki-67 expression detected by immunohistochemistry found that positive Ki-67 expression tends to be responsive to neoadjuvant chemotherapy 20 (76.9\%) and negative Ki-67 expression tends to be nonresponsive to neoadjuvant chemotherapy 12 (54.5\%); there were statistically significant differences with $p$ value $=0.025(p<0.05)$. This result suggests that Ki-67 expression detected by immunohistochemistry may predict clinical response to neoadjuvant chemotherapy in locally advanced breast cancer.

3.5. Relation of Ki-67 mRNA Expression with Neoadjuvant Chemotherapy Response. Based on qRT-PCR examination, we found that the mean value of Ki-67 mRNA expression was $11.241 \pm 1.971$. We determine Ki-67 mRNA expression cut-off point as 9.235, using receiver operating characteristics curve (ROC). Then Ki-67 mRNA expression was categorized as high level if it was $\geq 9.235$ and low level $<9.235$.

To find out whether Ki-67 mRNA expression has a relationship with clinical response to neoadjuvant chemotherapy in breast cancer, we used bivariate analysis, which can be seen in Table 3.

Analysis of Ki-67 mRNA expression detected by qRTPCR found that a high level of Ki-67 mRNA expression tends to be responsive to neoadjuvant chemotherapy, $16(76.2 \%)$,
TABLE 3: Relationships between Ki-67 mRNA expression with chemotherapy response in breast cancer.

\begin{tabular}{|c|c|c|c|}
\hline \multirow{2}{*}{ Ki-67 mRNA expression } & \multicolumn{2}{|c|}{ Chemotherapy response } & \multirow{2}{*}{ Total } \\
\hline & Responsive & Nonresponsive & \\
\hline High & $16(76.2 \%)$ & $5(23.8 \%)$ & $21(100 \%)$ \\
\hline Low & $1(11.1 \%)$ & $8(88.9 \%)$ & $9(100 \%)$ \\
\hline Total & $17(56.7 \%)$ & $13(43.3 \%)$ & $30(100 \%)$ \\
\hline
\end{tabular}

TABLE 4: Relationship between Ki-67 expression by immunohistochemistry and Ki-67 mRNA expression detected by qRT-PCR.

\begin{tabular}{lccc}
\hline \multirow{2}{*}{ Ki-67 expression } & \multicolumn{2}{c}{ Ki-67 mRNA expression } & \multirow{2}{*}{ Total } \\
& High & Low & \\
\hline Positive & $15(88.2 \%)$ & $2(11.8 \%)$ & $17(100 \%)$ \\
Negative & $6(46.2 \%)$ & $7(53.8 \%)$ & $13(100 \%)$ \\
\hline Total & $21(70 \%)$ & $9(30 \%)$ & $48(100 \%)$ \\
\hline
\end{tabular}

Spearman's $p=0.012(p>0,05)$.

and low level of Ki-67 mRNA expression tends to be nonresponsive to neoadjuvant chemotherapy, $8(88.9 \%)$. There were statistically significant differences with $p$ value $=0.002$ $(p<0.05)$. This result suggests that Ki-67 mRNA expression detected by qRT-PCR may predict clinical response to neoadjuvant chemotherapy in locally advanced breast cancer.

3.6. Relationship between Ki-67 Expression with Neoadjuvant Chemotherapy Response. To find out whether Ki-67 expression by immunohistochemistry has a relationship with Ki-67 mRNA expression detected by qRT-PCR, we used bivariate analysis, which can be seen in Table 4 .

Analysis of Ki-67 expression by immunohistochemistry and qRT-PCR found that a high level of Ki-67 mRNA expression tends to have positive Ki-67 expression, 15 (88.2\%), and low level of $\mathrm{Ki}-67 \mathrm{mRNA}$ expression tends to have negative Ki-67 expression, 7 (53.8\%). There were statistically significant differences with $p$ value $=0.012(p<0.05)$. This 
TABLE 5: Multivariate regression analysis for predictive factors.

\begin{tabular}{lccc}
\hline Variable & OR & $95 \%$ CI & $p^{*}$ \\
\hline Age & 2.553 & $0.018-1.508$ & 0.110 \\
Grading & 0.063 & $0.158-4.160$ & 0.802 \\
Subtype & 0.528 & $0.134-2.516$ & 0.468 \\
Ki-67 (IHC) & 0.133 & $0.124-20.969$ & 0.716 \\
Ki-67 mRNA Expression & 4.385 & $1.206-286.53$ & 0.036 \\
\hline
\end{tabular}

${ }^{*}$ Binary logistic regression analysis.

result suggests that Ki-67 mRNA expression detected by qRTPCR and Ki-67 expression using IHC have similar results.

3.7. Multivariate Analysis. Multivariate binary logistic regression analysis was used to determine independent predictors of clinical response to neoadjuvant chemotherapy in locally advanced breast cancer. Data shown in Table 5 revealed that Ki67 mRNA expression was an independent predictor for neoadjuvant chemotherapy in locally advanced breast cancer (OR, 4.385; CI, 1.206-286.53; $p=0.036$ ).

\section{Discussion}

From this study, we collected variable ages: the youngest was 29 years old and the oldest was 74 years old, with a median age of 46 years old, and the most populated age found was in the 4 th decade, as many as $40.5 \%$.

Globally, breast cancer patient $<50$ years old is $33 \%$ of the population; meanwhile, in Asia-Pacific, it is $42 \%$, in SouthEast Asia it is $47 \%$, and, in Australia, it is $21 \%$. SEER data in America showed breast that cancer is common in 55-64-yearold group of age, with a median age of 61 years old [20].

Several kinds of literature mentioned that generally the age of breast cancer patient is younger in Asia than in Europe and America. This difference possibly is caused by lifestyle factors, diet pattern, or the existence of certain gene which is related to race so that the difference in age occurred [20].

From the study, data obtained are as follow low grade $16.7 \%$, moderate grade $54.2 \%$, and high-grade $29.2 \%$. Histopathology grading is a particular prognostic factor. Some newest studies confirm the importance of histopathology grading as a predictive and prognostic factor in breast cancer. Engstrøm et al.'s study showed in the first five years, grade 2 and 3 breast cancer had a poorer prognosis than grade $1[21,22]$.

Breast cancer subtype is influencing chemotherapy response. Rouzier et al.s study showed that a complete pathologic response rate in Basal-like subtype is as much as $45 \%$ and Her2 is as much as $45 \%$; meanwhile luminal had a pathological complete response rate of $6 \%$ and no complete pathological response rate in normal-like subtype [23]. Luangdilok et al.'s study mentioned that complete pathological response in triple-negative subtype was $19.2 \%$ and Her2 was $24.2 \%$. Meanwhile, Luminal A was $4.4 \%$, and Luminal B was $9.7 \%$ [22]. A study of 102 breast cancer patients obtained complete pathological response in $16(15.7 \%)$ patients. Pathological complete response that is appropriate with different subtypes is as follows: Luminal A: 0 out of 20 (0\%), Luminal B: 2 out of $23(8.7 \%), \operatorname{Her} 2(+): 4$ out of $18(22.2 \%)$, and triple negative: 10 out of $41(24.4 \%)(p=0.041)$ [22]. Horimoto et al's study mentioned that Luminal B - Her2(-) patient who received chemotherapy had a pathological complete response rate $35 \%$ which is related to disease-free survival $[23,24]$.

Proliferation activity has prognostic information. Measurement of proliferation activity using Ki-67 detected by IHC is still controversy [25]; whether Ki-67 scores have much prognostic information and could predict the benefit of the addition of cytotoxic chemotherapy is still a question [25-27].

Several studies had investigated Ki-67 prognostic significance in breast cancer. The study shows that Ki-67 overexpression correlates with disease-free survival and overall survival $[22,28-30]$. However, a patient with high proliferation rate has a better response toward chemotherapy $[8,29]$. Furthermore, this marker may help the screening of patient who might not get any advantage from chemotherapy: those who have Her2 positive and negative hormonal receptor and low proliferation tumor $[8,22,29]$.

Studies revealed that $\mathrm{Ki}-67$ protein expression correlates with response to chemotherapy. High Ki-67 proliferation rate was predictive of a higher probability of complete pathological response [26]. Fasching et al. investigated Ki-67 by IHC of 552 patients and found that Ki-67 expression with $13 \%$ cutoff could predict complete pathological response with $94 \%$ sensitivity and $36 \%$ specificity $[13,29]$. Kim et al. found that Ki-67 expression with cutoff value $25 \%$ in breast cancer tissue is a predictor of neoadjuvant chemotherapy response. $\mathrm{Ki}-67$ is also a predictive factor for complete pathological response in ER-negative and HER2-positive breast cancer patients [31]. Wang et al. found that Ki-67 independently correlated with complete pathological response and clinical response, grades, and node status. Reduction of Ki-67 expression after neoadjuvant chemotherapy was observed in patients with a relatively better response [32]. Research of Ki-67 expression measured using quantitative immunofluorescence automated quantitative analysis (AQUA) technology found that high Ki-67 levels are a predictor of neoadjuvant chemotherapy response [33].

In our previous study, we found an insignificant correlation between expression of mRNA Ki- 67 baseline with chemotherapy response. But, chemotherapy cause decrease in mRNA expression of Ki-67. The rate of Ki-67 mRNA expression has a significant correlation with clinical response to chemotherapy [17, 34].

Several studies have found that changes before and after therapy in Ki-67 are a strong and independent predictor of disease-free time and survival rate $[13,35,36]$. The expression before and after chemotherapy can be a significant independent predictor of the overall survival in multivariate analysis. For this reason, nowadays, tumor response on neoadjuvant chemotherapy tryout is evaluated with the examination of immunohistochemistry Ki-67 [37].

Tumors with Ki-67 mRNA expression were examined by qRT-PCR associated with disease-free survival and overall survival of patients treated with adjuvant chemotherapy regimens. The results showed that the tumor with a high level of KI67 mRNA expression might be valuable for adjuvant therapy using docetaxel [38]. 
Studies found that high mRNA expression of Ki-67 was associated with a higher rate of the complete pathological response $(36.4 \%)$ compared with low levels mRNA Ki-67 (5.8\%). mRNA expression of Ki-67 is a predictor of the achievement of complete pathological response and better than Ki-67 expression which was detected by immunohistochemistry [39]. Ki-67 mRNA expression level is more objective and highly reproducible quantification of proliferation activity and more meaningful than $\mathrm{Ki}-67$ protein expression by immunohistochemistry, either by visual scoring or by quantitative image analysis [17, 39].

\section{Conclusion}

These results suggest that $\mathrm{Ki}-67$ expression detected by both IHC and qRT-PCR is considered to be predictor of clinical response to neoadjuvant chemotherapy in locally advanced breast cancer. This result also suggests that Ki-67 mRNA expression detected by qRT-PCR and Ki-67 expression using IHC have similar results.

\section{Conflicts of Interest}

The authors have no conflicts of interest to declare.

\section{Acknowledgments}

The authors very gratefully thank all breast cancer patients who were willing to be a respondent in this study.

\section{References}

[1] M. Wahidin, R. Noviani, S. Hermawan, V. Andriani, A. Ardian, and H. Djarir, "Population-based cancer registration in Indonesia," Asian Pacific Journal of Cancer Prevention, vol. 13, no. 4, pp. 1709-1710, 2012.

[2] C. H. Ng, N. Bhoo Pathy, N. A. Taib et al., "Comparison of breast cancer in Indonesia and Malaysia - a clinico-pathological study between dharmais cancer centre Jakarta and university Malaya medical centre, Kuala Lumpur," Asian Pacific Journal of Cancer Prevention, vol. 12, no. 11, pp. 2943-2946, 2011.

[3] M. Kaufmann, G. N. Hortobagyi, A. Goldhirsch et al., "Recommendations from an international expert panel on the use of neoadjuvant (primary) systemic treatment of operable breast cancer: an update," Journal of Clinical Oncology, vol. 24, no. 12, pp. 1940-1949, 2006.

[4] G. Fountzilas, U. Dafni, M. Bobos et al., "Evaluation of the prognostic role of centromere 17 gain and HER2/topoisomerase II alpha gene status and protein expression in patients with breast cancer treated with anthracycline-containing adjuvant chemotherapy: Pooled analysis of two Hellenic Cooperative Oncology Group (HeCOG) phase III trials," BMC Cancer, vol. 13, article 163, 2013.

[5] R. M. Connolly and V. Stearns, "Current approaches for neoadjuvant chemotherapy in breast cancer," European Journal of Pharmacology, vol. 717, no. 1-3, pp. 58-66, 2013.

[6] L. Santarpia, Y. Qi, K. Stemke-Hale et al., "Mutation profiling identifies numerous rare drug targets and distinct mutation patterns in different clinical subtypes of breast cancers," Breast Cancer Research and Treatment, vol. 134, no. 1, pp. 333-343, 2012.
[7] R. L. Jones, J. Salter, R. A'Hern et al., "The prognostic significance of Ki67 before and after neoadjuvant chemotherapy in breast cancer," Breast Cancer Research and Treatment, vol. 116, no. 1, pp. 53-68, 2009.

[8] R. Burcombe, G. D. Wilson, M. Dowsett et al., "Evaluation of Ki-67 proliferation and apoptotic index before, during and after neoadjuvant chemotherapy for primary breast cancer," Breast Cancer Research, vol. 8, no. 3, article R31, 2006.

[9] A. Goldhirsch, W. C. Wood, A. S. Coates, R. D. Gelber, B. Thürlimann, and H.-J. Senn, "Strategies for subtypes-dealing with the diversity of breast cancer: highlights of the St Gallen international expert consensus on the primary therapy of early breast cancer 2011," Annals of Oncology, vol. 22, no. 8, pp. 17361747, 2011.

[10] A. Goldhirsch, E. P. Winer, A. Coates, R. Gelber, M. PiccartGebhart, B. Thürlimann et al., "Personalizing the treatment of women with early breast cancer: highlights of the St Gallen International Expert Consensus on the Primary Therapy of Early Breast Cancer 2013," Annals of Oncology, vol. 24, no. 9, pp. 2206-2223, 2013.

[11] G. Gasparini, M. Barbareschi, C. Doglioni et al., "Expression of bcl-2 protein predicts efficacy of adjuvant treatments of operable node-positive breast cancer," Clinical Cancer Research, vol. 1, no. 2, pp. 189-198, 1995.

[12] M. E. H. Hammond, D. F. Hayes, M. Dowsett, D. C. Allred, K. L. Hagerty, S. Badve et al., "American Society of Clinical Oncology/College of American Pathologists guideline recommendations for immunohistochemical testing of estrogen and progesterone receptors in breast cancer (unabridged version)," Archives of Pathology \& Laboratory Medicine, vol. 134, no. 4, pp. e48-e72, 2010.

[13] H.-P. Sinn, A. Schneeweiss, M. Keller et al., "Comparison of immunohistochemistry with PCR for assessment of ER, PR, and $\mathrm{Ki}-67$ and prediction of pathological complete response in breast cancer," BMC Cancer, vol. 17, no. 1, article 124, 2017.

[14] E. Luporsi, F. André, F. Spyratos et al., "Ki-67: Level of evidence and methodological considerations for its role in the clinical management of breast cancer: Analytical and critical review," Breast Cancer Research and Treatment, vol. 132, no. 3, pp. 895915, 2012.

[15] N. Iqbal and N. Iqbal, "Human Epidermal Growth Factor Receptor 2 (HER2) in cancers: overexpression and therapeutic implications," Molecular Biology International, vol. 2014, pp. 1-9, 2014.

[16] R. Boom, C. J. A. Sol, M. M. M. Salimans, C. L. Jansen, P. M. E. Wertheim-Van Dillen, and J. van der Noordaa, "Rapid and simple method for purification of nucleic acids," Journal of Clinical Microbiology, vol. 28, no. 3, pp. 495-503, 1990.

[17] P. Prihantono, "Profile of mRNA expression of Ki-67 in breast cancer patients pre- and post- chemotherapy," American Journal of Clinical and Experimental Medicine, vol. 5, no. 1, p. 10, 2017.

[18] M. Mitas, K. Mikhitarian, C. Walters et al., "Quantitative realtime RT-PCR detection of breast cancer micrometastasis using a multigene marker panel," International Journal of Cancer, vol. 93, no. 2, pp. 162-171, 2001.

[19] P. Potemski, E. Pluciennik, A. K. Bednarek et al., "Ki-67 expression in operable breast cancer: a comparative study of immunostaining and a real-time RT-PCR assay," PathologyResearch and Practice, vol. 202, no. 7, pp. 491-495, 2006.

[20] N. Howlader, A. Noone, M. Krapcho, N. Neyman, R. Aminou, W. Waldron et al., SEER Cancer Statistics Review, 1975-2008, National Cancer Institute, Bethesda, Md, USA, 2011. 
[21] M. J. Engstrøm, S. Opdahl, A. I. Hagen et al., "Molecular subtypes, histopathological grade and survival in a historic cohort of breast cancer patients," Breast Cancer Research and Treatment, vol. 140, no. 3, pp. 463-473, 2013.

[22] S. Luangdilok, N. Samarnthai, and K. Korphaisarn, "Association between pathological complete response and outcome following neoadjuvant chemotherapy in locally advanced breast cancer patients," Journal of Breast Cancer, vol. 17, no. 4, pp. 376385, 2014.

[23] R. Rouzier, C. M. Perou, W. F. Symmans et al., "Breast cancer molecular subtypes respond differently to preoperative chemotherapy," Clinical Cancer Research, vol. 11, no. 16, pp. 5678-5685, 2005.

[24] Y. Horimoto, A. Arakawa, M. Tanabe et al., "Ki67 expression and the effect of neo-adjuvant chemotherapy on luminal HER2negative breast cancer," BMC Cancer, p. 550, 2014.

[25] A. S. Coates, E. P. Winer, A. Goldhirsch et al., "Tailoring therapies-improving the management of early breast cancer: St Gallen International Expert Consensus on the Primary Therapy of Early Breast Cancer 2015," Annals of Oncology, vol. 26, no. 8, pp. 1533-1546, 2015.

[26] E. De Azambuja, F. Cardoso, G. De Castro et al., "Ki-67 as prognostic marker in early breast cancer: a meta-analysis of published studies involving 12,155 patients," British Journal of Cancer, vol. 96, no. 10, pp. 1504-1513, 2007.

[27] C. Criscitiello, D. Disalvatore, M. De Laurentiis et al., "High Ki-67 score is indicative of a greater benefit from adjuvant chemotherapy when added to endocrine therapy in Luminal B HER2 negative and node-positive breast cancer," The Breast, vol. 23, no. 1, pp. 69-75, 2013.

[28] R. Haque, S. A. Ahmed, G. Inzhakova et al., "Impact of breast cancer subtypes and treatment on survival: an analysis spanning two decades," Cancer Epidemiology, Biomarkers \& Prevention, vol. 21, no. 10, pp. 1848-1855, 2012.

[29] P. A. Fasching, K. Heusinger, L. Haeberle et al., "Ki67, chemotherapy response, and prognosis in breast cancer patients receiving neoadjuvant treatment," BMC Cancer, vol. 11, article 486, 2011.

[30] E. C. Inwald, M. Klinkhammer-Schalke, F. Hofstädter et al., "Ki67 is a prognostic parameter in breast cancer patients: Results of a large population-based cohort of a cancer registry," Breast Cancer Research and Treatment, vol. 139, no. 2, pp. 539-552, 2013.

[31] K. I. Kim, K. H. Lee, T. R. Kim, Y. S. Chun, T. H. Lee, and H. K. Park, "Ki-67 as a predictor of response to neoadjuvant chemotherapy in breast cancer patients," Journal of Breast Cancer, vol. 17, no. 1, pp. 40-46, 2014.

[32] R.-X. Wang, S. Chen, X. Jin, and Z.-M. Shao, "Value of Ki67 expression in triple-negative breast cancer before and after neoadjuvant chemotherapy with weekly paclitaxel plus carboplatin," Scientific Reports, vol. 6, Article ID 30091, 2016.

[33] J. R. Brown, M. P. Digiovanna, B. Killelea, D. R. Lannin, and D. L. Rimm, "Quantitative assessment Ki-67 score for prediction of response to neoadjuvant chemotherapy in breast cancer," Laboratory Investigation, vol. 94, no. 1, pp. 98-106, 2014.

[34] P. Prihantono, The Role of $m R N A$ Expression of TOP2A, BCL2 and Ki-67 as Predictors of Clinical Response for Neoadjuvant Chemotherapy using Cyclophosphamide-Adriamicin-5FU (CAF) Regimen in Locally Advanced Breast Cancer, Universitas Hasanuddin, Makassar, Indonesia, 2017, http://repository.unhas .ac.id/handle/123456789/25175.
[35] M. Colozza, E. Azambuja, F. Cardoso, C. Sotiriou, D. Larsimont, and M. J. Piccart, "Proliferative markers as prognostic and predictive tools in early breast cancer: where are we now?" Annals of Oncology, vol. 16, no. 11, pp. 1723-1739, 2005.

[36] R. Nishimura, T. Osako, Y. Okumura, M. Hayashi, and N. Arima, "Clinical significance of Ki-67 in neoadjuvant chemotherapy for primary breast cancer as a predictor for chemosensitivity and for prognosis," Breast Cancer, vol. 17, no. 4, pp. 269$275,2010$.

[37] N. Niikura, T. Iwamoto, S. Masuda et al., "Immunohistochemical Ki67 labeling index has similar proliferation predictive power to various gene signatures in breast cancer," Cancer Science, vol. 103, no. 8, pp. 1508-1512, 2012.

[38] R. M. Wirtz, H. Sihto, J. Isola et al., "Biological subtyping of early breast cancer: a study comparing RT-qPCR with immunohistochemistry," Breast Cancer Research and Treatment, vol. 157, no. 3, pp. 437-446, 2016.

[39] F. Marme, A. Schneeweiss, J. Aigner et al., "Abstract P3-0608: Ki-67 mRNA as a predictor for response to neoadjuvant chemotherapy in primary breast cancer," Cancer Research, vol. 72, no. 24, 2014. 


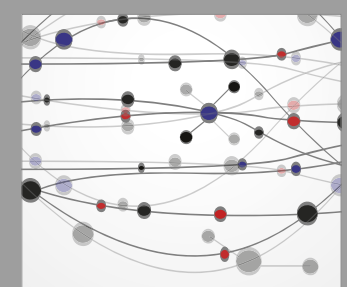

The Scientific World Journal
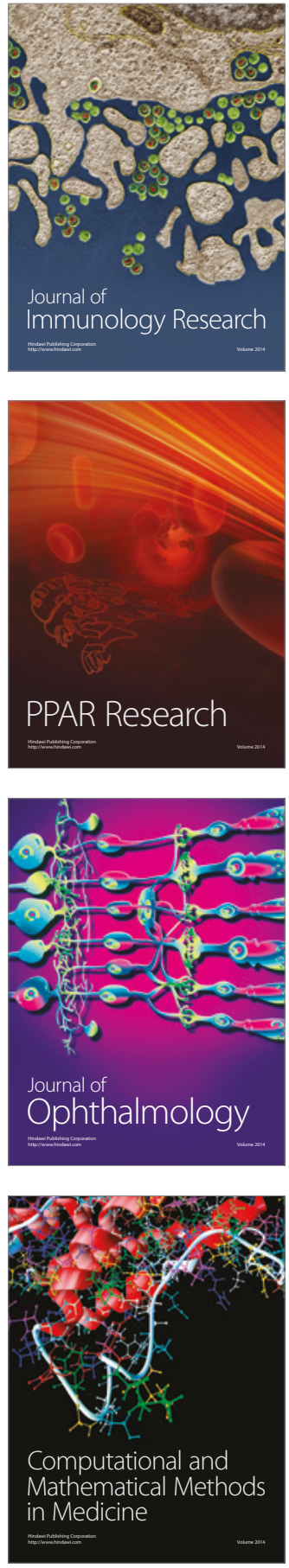

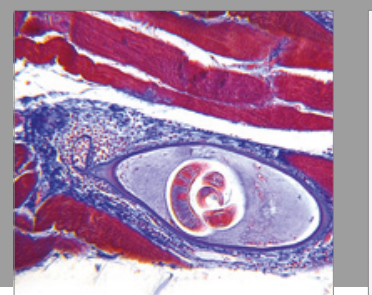

Gastroenterology Research and Practice
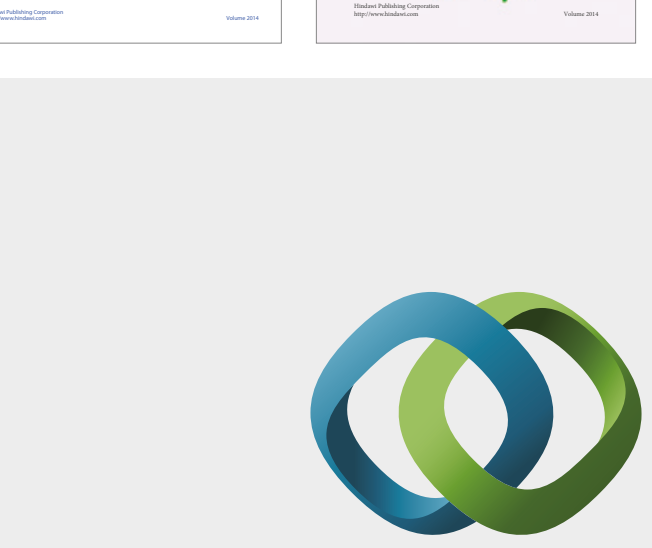

\section{Hindawi}

Submit your manuscripts at

https://www.hindawi.com
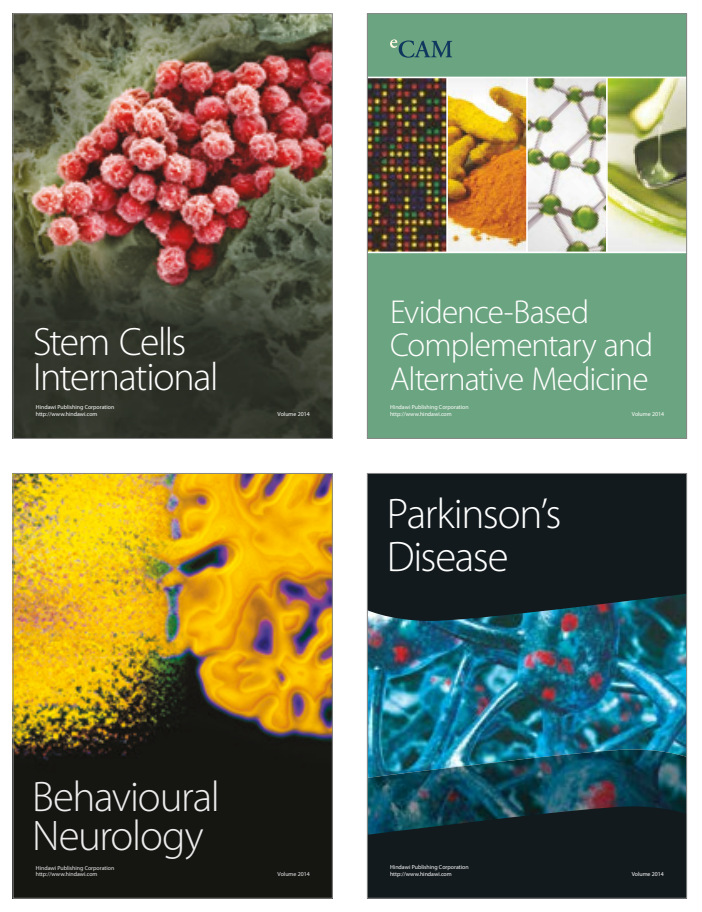
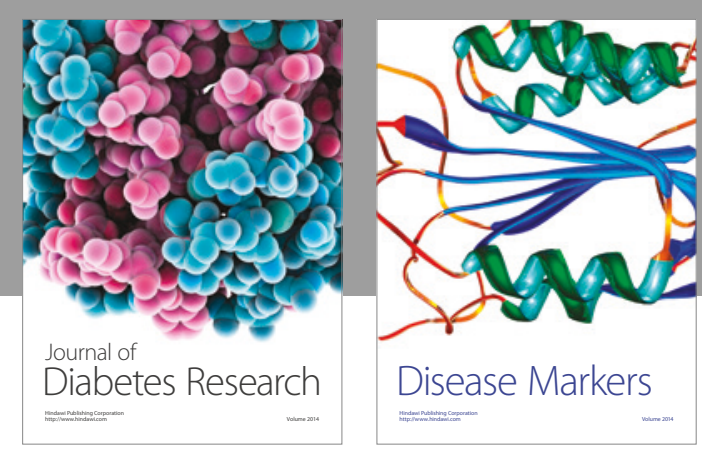

Disease Markers
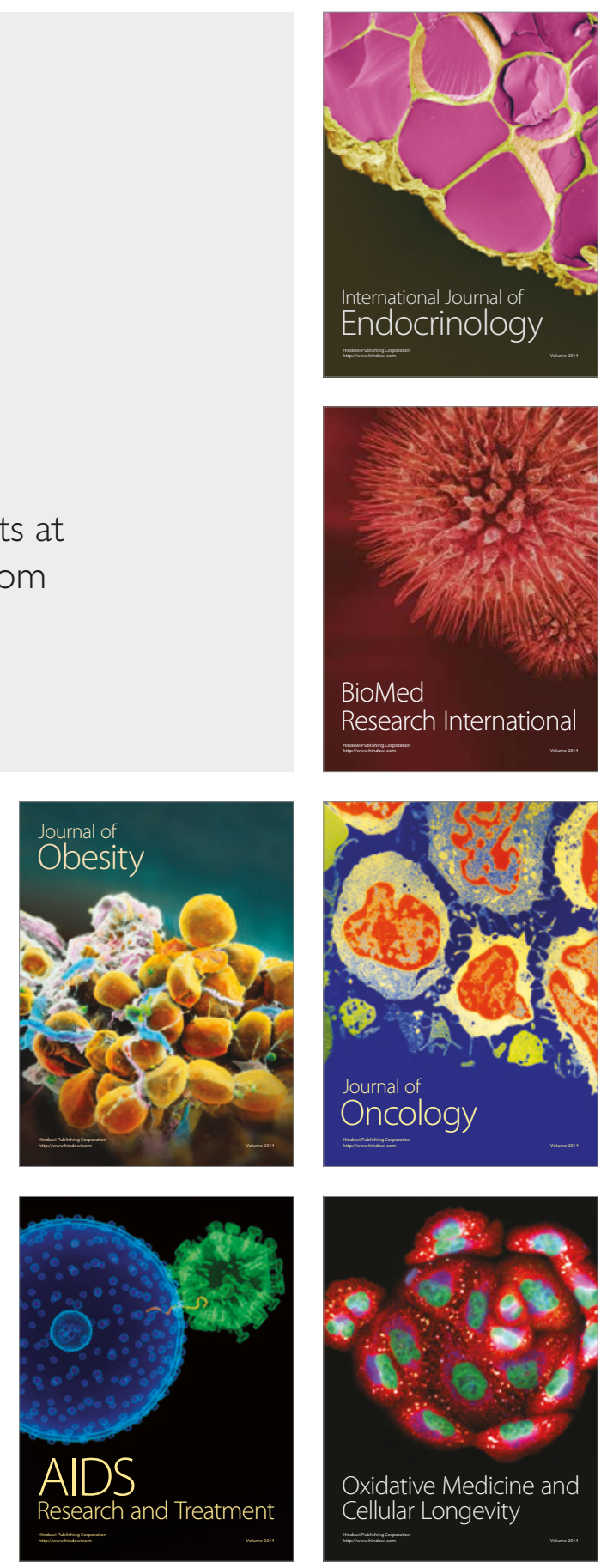